\title{
UNUSUAL CAUSE OF SUBLUXATION OF AUSTIN MOORE PROSTHESIS OF THE HIP
}

\author{
N.C.E. Okpala \\ St. Georges Healthcare NHS Trust, \\ Blackshaw Road, Tooting, London SW17 OQT \\ United Kingdom
}

\begin{abstract}
Subluxation and dislocation following hip arthroplasty is a well known complication. It can be due to a number of reasons - varying from malrotation of the component, operative approach, previous surgery, previous stroke, loosening and high wear rates of prosthesis, infection to even patient behaviour. In this study, an unusual cause of subluxation of the hip caused by impinging tissue - prolapsed fat is reported in an 88 year-old female in a Northern England hospital. Post-operative check x-rays showed a subluxed Austin Moore propthesis. It was successfully surgically corrected. In a large number of cases of subluxations, no cause can be found. Re-operations have been found to be most successful when a precise determination of the cause of instability is made and appropriate measures applied.
\end{abstract}

Keywords: $\quad$ Subluxation, dislocation, Austin Morre Prosthesis, hip arthroplasty

\section{INTRODUCTION}

Subluxation and dislocation following hip arthroplasty is a well known complication with rates varying from $1-10 \%$ for different prostheses (Barnes et al., 1995; Fender et al., 1999; Champion and McNally, 2004) while its evidence seems to be associated with surgeon experience considering incidence among large centres (Barnes et al., 1995). The causes of instability vary from malrotation of the component, disruption of the trochanteric-abduction mechanism, impingement to infection. Subluxation can also be due to loosening and high wear rates of prosthesis; loss of material e.g. cement and loss of elasticity. Patient behaviour can also account for complication following surgery including subluxation e.g. Japanese sitting position, horse riding. There are reported increased rates in those with cerebrial palsy (Willamann, 2001; Kaneko et al., 2004). In a number of cases, no cause can be found.

Re-operations have been found to be most successful when a precise determination of the cause of instability is made with appropriate measures 
(Daly and Morrey, 1992). An unusual cause of subluxation of the hip is reported.

\section{CASE REPORT}

An 88 year-old female presented to a hospital in Northern England following a fall. She complained of pain and swelling of the right leg. Xray showed fracture of the right tibia and fibula. She subsequently complained of pain in the back and left thigh of about four days duration. X-ray of the left hip revealed a sub-capital fracture of the left neck of the fermur (Plate 1). She had an Austin Moore hemiarthroplasty.

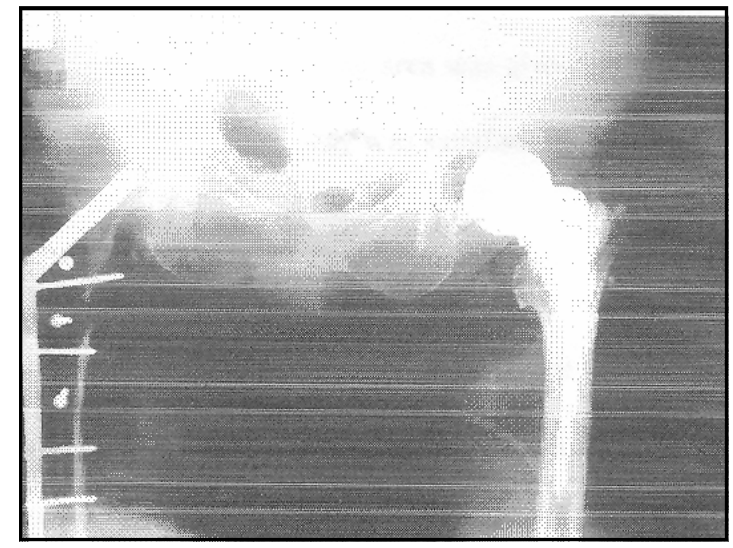

Plate 1: X-ray showing subluxation

Operation showed a very soft osteoporotic bone. This was confirmed by histology. After the fitting of the prosthesis, reduction was stable in full $90^{\circ}$ flexion, external and internal rotation.

Post-operative check $\mathrm{x}$-rays showed a subluxed Austin Moore prosthesis (Plate 2). Weight bearing on the leg was painful. The x-rays showed an odd-looking hazy shadow in the acetabulum. After a few days, the situation did not look better so she had to be re-explored. At the reexploration, the acetabulum was full of fat from the synovial folds and the surrounding area was also swollen. All of this was excised and the hip reduced well. Check X-ray was satisfactory.

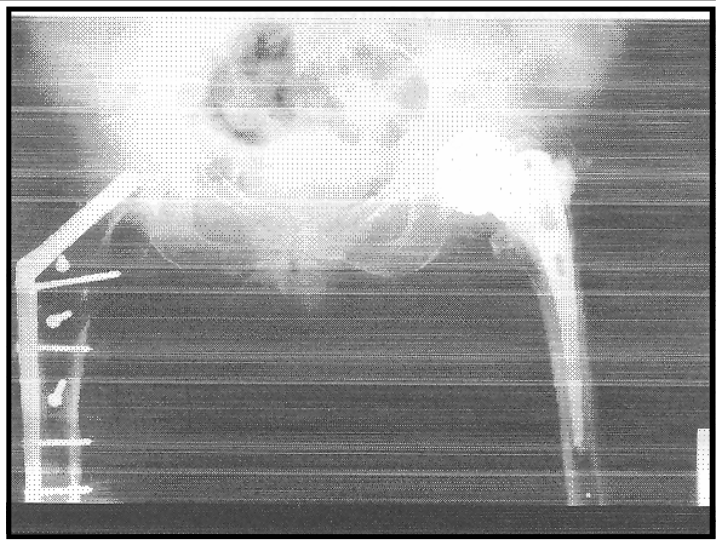

Plate 2: Subluxation corrected

\section{DISCUSSION}

Hemiarthroplasty is carried out for sub-capital fractures of the neck of fermur especially when the fracture is displaced (Garden III and IV). It is done using various types of prostheses which include the Austin Moore's, Hastings and Thompson's prostheses.

The incidence of dislocations/subluxations varies in reports. Revision hip surgeries in the elderly appear to have a higher dislocation rate up to $20 \%$ when compared to primary surgery (Radcliff et al., 1999). Various factors including operative approach, the anteversion of the implant, previous surgery, previous stroke and infection have all been reported as contributing factors (Dorr et al., 1983; Champion and McNally, 2004). Infection is present in up to $33 \%$ of dislocated neck prosthesis. That is why, in the absence of definite mechanical aetiology, infection must be ruled out. This particular report shows a subluxation secondary to prolapsed fat from the synovial folds.

The prolapsed fat was not noticed postoperatively and there was nothing in the surgical approach to account for this. The surgeon was fairly experienced with an overall low rate of subluxation/dislocation. More careful and judicious surgical approach would most likely lead to lower subluxation rate. Dislocations with iden-

32 Journal of Science and Technology, Volume 27 no. 2, August, 2007 
tifiable cause tend to have a better outcome while outcomes for the treatment of instability with no identifiable are unpredictable (Parvizi and Morrey, 2000). Even when a correctable cause such as component malpositioning is found and corrected, the success rate is approximately two out of three (Daly and Morrey, 1992). In this case, surgical correction was indeed successful. Surgical options for treatment include revision to correct the component's position, trochanteric advancement, improvement of soft-tissue tensioning by increasing offset, removal of impinging tissue (which was prolapsed fat in this case report), augmentation of the acetabular lining, bipolar arthroplasty, and insertion of a constrained cup mechanism.

\section{ACKNOWLEDGEMENTS}

The author is grateful to the staff of the hospital. $\mathrm{He}$ is also grateful to his younger brother, Odili Okpala of the Kwame Nkrumah University of Science and Technology, Kumasi-Ghana, for his contribution in preparation and proof reading of the manuscript.

\section{REFERENCES}

Barnes, C.L., Berry, D.J., and Sledge, C.B. (1995). Dislocation after bipolar hemiarthroplasty of the hip. J. Arthroplasty 10: 667.

Champion, L.M.V. and McNally, S.A. (2004). Dislocation after revision of hemiarthroplasty to total hip replacement. Injury, Int. J. Care Injured 35: 161-164.

Daly, P.J. and Morrey, B.F. (1992). Operative correction of an unstable total hip arthroplast. J. Bone Joint Surg. Am 74(9): 133443.
Dorr, L.D., Wolf, A.W., Chandler, R.W. and Conaty, J.P. (1983). Classification and treatment of dislocations of primary total hip arthroplasty. Clin Orthop 173: 151-158.

Kaneko, K., Murotani, R., Mogami, A., Okahara, H., Ohbayashi, O., Iwase, H., Fujita, H. and Kurosawa, H. (2004). Subluxation of the hip joint after internal fixation of a trochanteric fracture. Injury 35(2): 203-6.

Fender, D., Harper, W.M. and Greeg, P.J. (1999). Outcome of Charnley total hip replacements across a single health region in England. J. Bone Joint Surg 81-B: 577.

Parvizi, J. and Morrey, B. (2000). Bipolar Hip Arthroplasty as a salvage treatment for instability of the hip. J. Bone Surg. Am 82-A: 1132-1139.

Radcliff, G.S., Tomachan, M.C., Andrews, M. and Stone, M.H. (1999). Revision hip surgery in the elderly-Is it worthwhile? $J \mathrm{Ar}$ throplasty $14: 38$

Shrader, M.W., Parvizi, J. and Lewallen, D.G. (2003). The use of a contrained acetabular component of treat instability after total hip arthroplasty. J. Bone Surg Am 85-A, 11321139.

Willmann G. (2001). Investigation of explanted hip and acetabulum hip prothesis Biomedizinische Technik 46(12): 343-50. 